\title{
Cardiac Arrhythmia following Stroke
}

\author{
(ㅇ)(1) (8) \\ Authors \\ Bernd Kallmünzer, Stefan Schwab \\ Affiliation \\ Department of Neurology, University Hospital Erlangen, Erlangen \\ Key words \\ stroke, arrhythmia, atrial fibrillation, embolism \\ Bibliography \\ DOI http://dx.doi.org/10.1055/s-0043-102263 \\ Neurology International Open 2017; 1: E8-E17 \\ (c) Georg Thieme Verlag KG Stuttgart - New York \\ ISSN 2511-1795 \\ Correspondence \\ Dr. med. Bernd Kallmünzer \\ Department of Neurology \\ University Hospital Erlangen \\ Schwabachanlage 6 \\ 91054 Erlangen \\ Germany \\ bernd.kallmuenzer@uk-erlangen.de
}

\begin{abstract}
One in 4 patients with acute stroke suffers from clinically relevant cardiac arrhythmia that may complicate the clinical course by hemodynamic instability, limit the success of rehabilitative care and increase the risk of stroke recurrence. A structured analysis of the continuous ECG recordings at the stroke unit can double the detection rate of paroxysmal atrial fibrillation compared to conventional monitoring. In case of suspected cardiac arrhythmia, ambulatory long-term heart rhythm monitoring is available for patients with stroke of unknown cause. Apart from the emergency management of arrhythmia, different aspects of the antithrombotic treatment for secondary prevention are of major therapeutic relevance and represent clinical challenges for the neurologist.
\end{abstract}

\section{Anatomical Background: Autonomic Innervation of the Heart}

The autonomous innervation of the heart is based on a complex interaction of central and peripheral mechanisms in sympathetic and parasympathetic parts of the autonomic nervous system ( Fig. 1). An extrinsic cardiac innervation is distinguished from an intrinsic one.

\section{Extrinsic system}

To put it simply, a center of the efferent parasympathetic innervation of the heart is found in the nucleus of the medulla oblongata, especially in the nucleus dorsalis [1]. The preganglionic fibers leave the central nervous system along with the vagus nerve and are connected to the second neuron in cardiac ganglion cells. Sympathetic fibers, on the other hand, originate from the nucleus intermediolateralis of the upper thoracic cord [2]. They reach the plexus cardiacus by means of the so-called "cardiac nerves" (usually 4 right-sided and 3 left-sided nervi cardiaci), after interposition in the border ganglia, especially in the ganglion stellatum. For the control of cardiac functions, the profound part of the plexus cardiacus is decisive; it extends between the tracheal bifurcation and the aortic arch, divides into a right and left half and in its further course follows the right or left coronary artery. The function of the efferent limb is modified by afferents from various organ systems, including the gastrointestinal tract or the carotissinus, by means of multisynaptic reflex arcs (e. g., baroreflex) [1]. In addition, in the blood circulating catecholamine, the release of which in the adrenal system is also subject to the autonomic system, mediates beta-adrenergic effects on the myocardium. It is postulated that dysbalances in the extrinsic system, in particular the pathological disinhibition of sympathetic activity, are relevant to the development of cardiac arrhythmias [1, 3-5]. For example, extensive brain stem damage can lead to suppression of central parasympathetic functions and overcoming of sympathetic tone [6], thus promoting the occurrence of cardiac arrhythmias. Conversely, blockade of the ganglion stellatum or renal sympathetic denervation should reduce the risk of ventricular arrhythmias in patients with prolonged-QT syndromes [7]. It is noteworthy in this context that extensive cardiac denervation, which may be present after orthotopic heart transplantation, is associated with a lower risk of supraventricular rhythm disturbances, especially atrial fibrillation [8]. In these cases, the denervation should have protective effects and protect the myocardium from the autonomic imbalances of the extrinsic system before transmission. It should be noted, however, that organ donors are usually much younger and the vascular damage to the donor organs is often less pronounced, which significantly reduces the risk of atrial fibrillation independent of cardiac denervation [9]. 


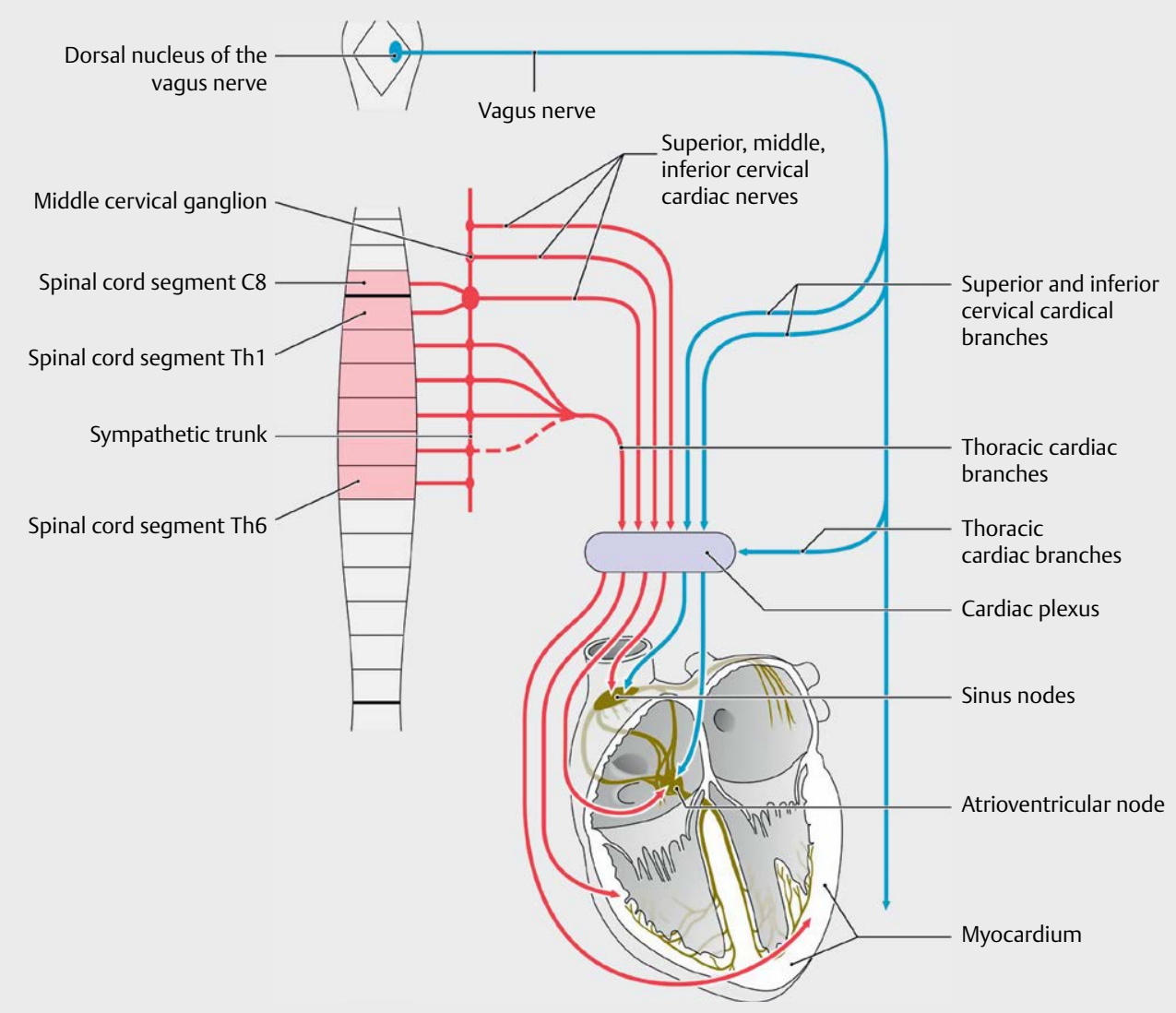

- Fig. 1 Extrinsic autonomic innervation of the heart. RVLM: Right ventrolateral medulla oblongata. CVLM: Central ventrolateral medulla oblongata. DMNX: Nucleus dorsalis nervi vagi. NTS: Nucleus tractus solitarii. NA: Nucleus ambiguous [67].

\section{Intrinsic system}

The intrinsic system of the cardiac innervation involves a differentiated network of up to 94000 neurons in approximately 1000 epicardial ganglions, which are closely connected to the extrinsic system and are divided into 3 anatomically defined groups (retriotrial, annulo-ventricular and aorto-pulmonary group) [10]. These neurons use various neurotransmitters, including bradykinin, nitric oxide, neuropeptide $\mathrm{Y}, \mathrm{CGRP}$ and substance $\mathrm{P}$, the functional significance of which is still unclear. A comparatively dense network of nerve endings is found particularly at the insertion the pulmonary veins in the left atrium, where it is associated with the development of atrial fibrillation [10]. In addition to the electrical isolation of the pulmonary vein opening from the atrial myocardium, initial clinical data indicate that the targeted ablation of autonomic ganglia could also exert an antiarrhythmic effect [11]. However, the identification of suitable epicardial ganglions and their selective ablation is technically sophisticated and currently has only limited clinical application.

\section{Superordinate cortical regulation}

More than 100 years ago, the presence of hemispheric regulatory mechanisms upstream to the autonomic centers of the brain stem and the hypothalamus was postulated [12]. This assumption resulted from the simple observation that many vegetative functions, including the increase in blood pressure and heart rate, began well before the beginning of an arbitrary movement to ensure a stable circulation. Underpinned by animal experimental studies and functional imaging, the mesiofrontal and insular regions have been considered to be of particular importance for these functions [13-16]. Inactivation (e. g., by ischemic lesions) as well as stimulation of these regions (e. g., epileptic seizures) may lead to central autonomic dysregulations [3]. In a study of patients with acute ischemic stroke and clinically relevant cardiac arrhythmia, the cerebral lesion pattern was more precisely characterized by voxel-based analysis [17]. Similar to earlier investigations, a "hotspot" was found in the insula region of the right hemisphere, which additionally underlines their importance for central autonomic regulation. Further significant associations were found with right frontal and right parietal cortex regions, the right amygdala, basal ganglia and thalamus.

\section{Bradycardic Arrhythmia}

In an observational study of 501 patients with acute stroke (92\% ischemic, $8 \%$ hemorrhagic) in a stroke unit (patients with indication for mechanical ventilation were excluded), bradycardic cardiac arrhythmias occurred in the first 3 days after admission in $42 \mathrm{pa}-$ tients (8.4\%) on [18] ( $\triangleright$ Fig. 2 ). These included 24 cases of atrial fibrillation with bradycardia (ventricular rate $<30 / \mathrm{min}$ for at least $30 \mathrm{~s}$ or pauses $>3 \mathrm{~s}$ ), 10 cases with high grade AV block, and 8 cases 

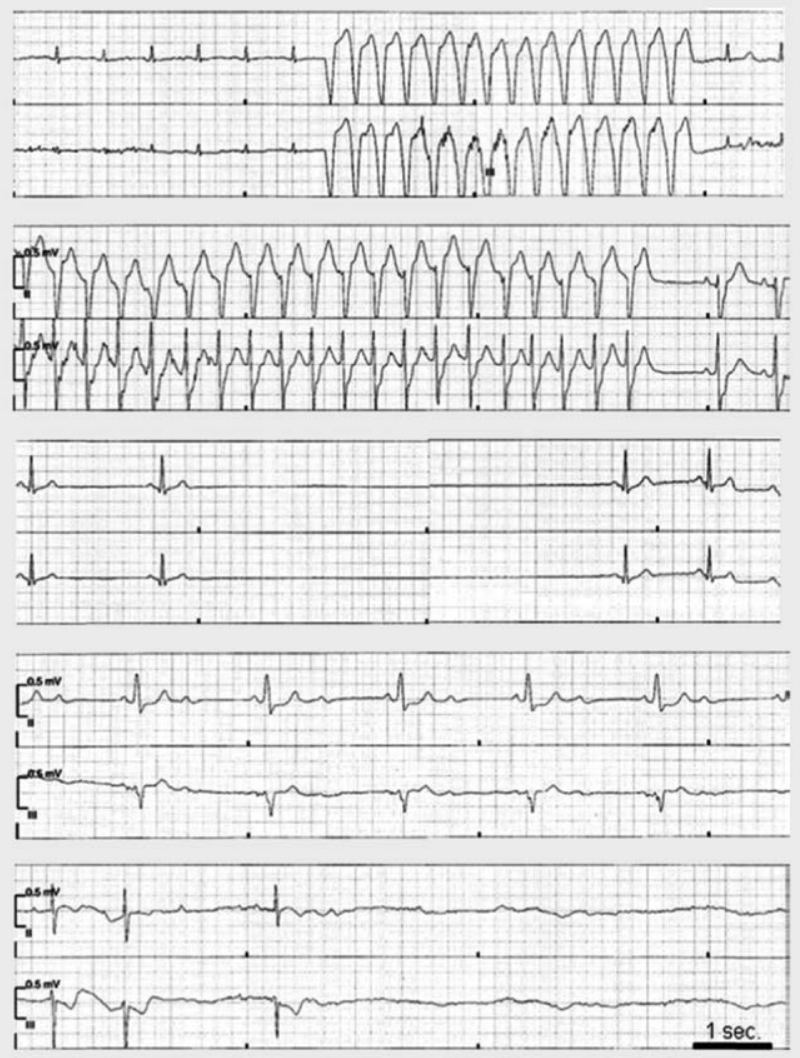

- Fig. 2 Examples of clinically relevant cardiac arrhythmias in patients with acute stroke, documented in continuous ECG monitoring. From top to bottom: non-sustained ventricular tachycardia, $H R=180 /$ min, spontaneous end of a supraventricular tachycardia with pre-existing bundle branch block, sinus arrest $>5 \mathrm{~s}$, AV block second degree, asystole with atril fibrillation with bradycardic transition [18].

with asystole/sinus arrest. One patient needed cardiopulmonal resuscitatsion. In 11 patients, the implantation of a heart pacemaker was necessary. In 21 patients, changes were made in drug therapy (e.g., therapy with ß-adrenoceptor blockers was stopped). In earlier studies on this subject, the incidence of bradycardic arhythmias was significantly lower. Thus, Rem and colleagues reported relevant bradycardia in only $3.2 \%$ of patients during 48 -h monitoring [19]. The duration and individual technical design of the monitoring is important for the sensitivity of the method, and monitoring the time that elapsed from the beginning of the symptoms is also important. Already in the ECG at admission, prolongation of the PQ interval or a bundle branch block morphology can be seen in more than $50 \%$ of patients (Bobinger T. et al., Manuscript in preparation). Interestingly, in a recent meta-analysis of 8 studies with several thousand patients, a significant correlation between PR interval prolongation and the risk of developing atrial fibrillation was observed (RR 1.45, $95 \% \mathrm{Cl} 1.23-1.71$ ) [20]. In this context, however, it should be borne in mind that an extension of the atrioventricular conduction in the 12-lead ECG can also be an expression of a drug therapy and about $30 \%$ of patients with acute stroke take antiarrhythmic drugs, most often a ß-adrenoceptor blocker [18]. In the study mentioned above, most bradycardias were ob-

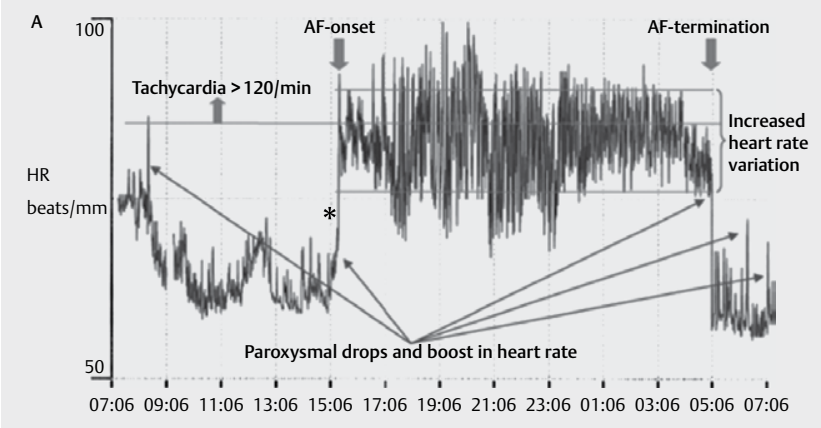

- Fig. 3 The quality of the ECG monitoring in the Stroke Unit can be improved by an additional analysis of data. For this purpose, a frequency profile is created at a 24-h interval. Paroxysmal episodes of atrial fibrillation are often manifested by frequency hopping, tachycardia/bradycardia, or changes in the frequency band [68].

served immediately during the first $12 \mathrm{~h}$ with a rapidly decreasing incidence until the third day after admission [18]. Future studies can use the new options for cardiac long-term monitoring to gain more accurate information on the risk of bradycardia in the medium and long term follow up, especially during the critical phase of physical exercise in neurorehabilitation.

\section{Tachycardic Arrhythmias}

Tachycardic arrhythmias are significantly more common in the acute phase after stroke than bradycardic ones [18]. Most of the cases are supraventricular tachycardias, usually atrial fibrillation with a tachycardic transition. Ventricular arrhythmias, on the other hand, are particularly important for the long-term course after stroke, as they are the leading cause of the sudden cardiac death $[3,5]$. In an American study (Northern Manhattan Study NOMAS [21]), out of 655 patients who had suffered an ischemic stroke for the first time, $37.3 \%$ had died within 5 years. In 44 patients, there was primary cardiac death, including most frequently sudden cardiac death, followed by fatal myocardial infarction and terminal heart failure. While the insular cortex is recognized as a vulnerable center of autonomic regulation [3], an association of fatal cardiac complications with infarcts of the parietal lobes was found unexpectedly in the NOMAS study, especially in the left hemisphere. An inhibitory influence of these parietal regions on the insular cortex, which breaks away after ischemic injury and thus causes a sympathetic disinhibition, was proposed as a model [22]. On the cellular level, it is assumed that an unphysiologically high probability of open calcium channel occurs due to the overwhelming activation of $ß$-adrenoceptors by the increased release of cAMP [23-25]. The increased intracellular calcium concentration in turn causes a metabolic imbalance and a myocardial relaxation disorder leading up to cell death and myocytolysis. Furthermore, the increased sympathetic tone may cause electrolyte disturbances in the serum, in particular hypokalemia and hypomagnesemia, which in turn favor the occurrence of arrhythmias [25]. A prolongation of the QT time is already evident in the 12-lead ECG as a sign of an increased risk of ventricular arrhythmia in a significant section of the patients [26]. According to our own investigations of a cohort with 1141 patients, 
- Table 1 Selection of studies on atrial fibrillation detection after stroke.

\begin{tabular}{|c|c|c|c|}
\hline $\begin{array}{l}\text { Method, } \\
\text { Duration }\end{array}$ & $\begin{array}{l}\text { Patient } \\
\text { number }\end{array}$ & $\begin{array}{l}\text { Detection } \\
\text { rate }\end{array}$ & Reference \\
\hline $\begin{array}{l}\text { Telemetry } \\
24 \mathrm{~h}\end{array}$ & $N=281$ & $4.6 \%$ & $\begin{array}{c}\text { Gruber et al., } \\
2012\end{array}$ \\
\hline $\begin{array}{l}\text { Telemetry with } \\
\text { review of data } \\
72 \mathrm{~h}\end{array}$ & $N=245$ & $7.3 \%$ & $\begin{array}{l}\text { Kallmünzer } \\
\text { et al., } 2012\end{array}$ \\
\hline $\begin{array}{l}\text { Holter ECG } \\
24 \mathrm{~h}\end{array}$ & $N=120$ & $2.5 \%$ & $\begin{array}{l}\text { Rizos et al., } \\
2010\end{array}$ \\
\hline $\begin{array}{l}\text { Holter-ECG } \\
3 \text { Tage }\end{array}$ & $N=1135$ & $4.3 \%$ & $\begin{array}{l}\text { Grond et al., } \\
2013\end{array}$ \\
\hline $\begin{array}{l}\text { Holter ECG } \\
7 \text { Days }\end{array}$ & $N=220$ & $12.7 \%$ & $\begin{array}{c}\text { Stahrenberg } \\
\text { et al., } 2010\end{array}$ \\
\hline $\begin{array}{l}\text { External event } \\
\text { recorder } \\
90 \text { Days }\end{array}$ & $N=\mathbf{2 8 0}$ & $16.1 \%$ & $\begin{array}{l}\text { Gladstone } \\
\text { et al., } 2014\end{array}$ \\
\hline $\begin{array}{l}\text { Implantable } \\
\text { event recorder } \\
6 \text { Months }\end{array}$ & $N=221$ & $8.9 \%$ & $\begin{array}{c}\text { Sanna et al., } \\
2014\end{array}$ \\
\hline
\end{tabular}

For all studies, only atrial fibrillation episodes of at least $30 \mathrm{~s}$ duration have been considered. For comparison: In a meta-analysis of 32 studies, the mean detection rate was $11.5 \%$ (95\% Cl: 8.9-14.3\%) [66]

an extension of the frequency-corrected QT time is present in $35 \%$ of patients with acute cerebral ischemia and in $44 \%$ of patients with intracerebral bleeding (Bobinger et al., Manuscript in preparation). As in earlier studies, this cohort also confirmed an extension of the QT period as a predictor of mortality in the 3-month course [27]. However, the early repolarization pattern, which has received much attention over the last 10 years, may be of secondary importance for stroke patients [28].

\section{Atrial Fibrillation}

\section{Frequency of ischemic stroke}

While older studies reported atrial fibrillation in about $20 \%$ of all strokes, the frequency is actually much higher according to recent studies. A cross-sectional study from Sweden reported $33.4 \%$ of a total of 94083 patients with an ischemic stroke between 2005 and 2010 suffered from atrial fibrillation [29]. It was repeatedly shown that up to $20 \%$ of patients with a stroke who were initially classified as "cryptogenic" had an unidentified, paroxysmal atrial fibrillation. In view of the great therapeutic relevance, this observation is the starting point for an intensification of the rhythmological diagnostics in stroke patients, which includes both the acute phase in the stroke unit and after discharge into ambulatory care ( $\triangleright$ Table 1).

\section{Embolies in atrial fibrillation: complex pathophysiology}

The Framingham Heart Study has shown that clinically manifest atrial fibrillation multiplies the risk of stroke by a factor of 5 , independent of other risk factors [30]. However, the underlying mech- anisms are still insufficiently understood. Up to now, the stasis of blood flow in the left atrium has been postulated as the cause of embolic complications during the atrial fibrillation episodes [31], in analogy to the Virchow triad. This, in turn, is a direct consequence of a disturbed atrial contraction and atrial dilatation. This approach appears to be intuitively correct but fails to convince as far an understanding of the large number of atrial fibrillation-associated stroke events is concerned. Most recently, newer data have raised serious questions about this approach [32-34]: In the ASSERT study, involving 2580 patients with implanted cardiac pacemaker or AICD aggregate groups, a total of 51 patients during follow-up of 2.5 years suffered an ischemic stroke or a systemic embolism. A reading of the pacemaker memory allowed to study the temporal relationship between atrial fibrillation episodes and the occurrence of stroke: In a period of 30 days before the occurrence of stroke, atrial fibrillation episodes $>6$ min were detectable in only n $8 \%$ of the cases. Much more frequently, the episodes occurred more than 30 days earlier, or occurred for the first time after a stroke [32].

Two further studies with similar methodologies also concluded that the majority of cardiac embolisms occur without immediately preceding episodes of atrial fibrillation [33, 34]. Modern concepts are therefore based on the assumption that episodes of atrial fibrillation are only "the tip of the iceberg" and the epiphenomena of a complex disease of the atria, with risk of stroke persisting even after conversion to sinus rhythm $[35,36]$. This would also explain why studies on rhythmization have so far yielded essentially no positive results with regard to embolism risk. The center of this atrial disease is possibly atrial fibrosis, which can be demonstrated by sequences showing late gadolinium enhancements in MRI and which, favored by prothrombotic triggers, predisposes to intracardiac thrombus formation [35].

In addition to changes in the plasmatic blood clotting (for instance, increased concentration of prothrombin fragments, D-dimers and increased expression of the von Willebrand factor), inflammatory processes (for example, increased interleukin 6, hsCRP, various growth factors) are also considered as possible triggers.

\section{Atrial fibrillation and stroke: cause or also consequence?}

The autonomic nervous system plays a key role in the pathophysiology of atrial fibrillation [37], which can be seen from the episodic fluctuations in the occurrence of paroxysmal atrial fibrillation. The highest risk is therefore to be found in the early morning and late evening as well as in the winter months [38]. On Saturdays, on the other hand, there are probably fewer episodes of atrial fibrillation than on weekdays. These observations suggest that autonomic imbalances may favor and may even be the cause of the first occurrence of atrial fibrillation [39]. It has been shown that patients with ischemic stroke are significantly more likely to have the first onset of atrial fibrillation episode in the first few hours after the start of neurological symptoms, when the insular cortex region as the center of the autonomic control suffers an injury [40]. It is reported that these patients lack the characteristic features which indicate a high cardiac embolism risk (e. g., proof of intracardiac thrombi or atrial dilatation) [41]. However, this could not be con- 
firmed by a recently published work on this subject [42]. It is also possible that the systemic inflammatory reaction associated with the ischemic brain damage is a trigger for the occurrence of atrial fibrillation [43]. However, since there are currently no reliable strategies to determine whether atrial fibrillation is a cause or a possible complication of a stroke, and it is not known whether the embolism risk of the 2 forms differ from each other, these considerations do not yet play a role in the indication for antithrombotic therapy. Patients should initiate oral anticoagulation as secondary prophylaxis of stroke if there are no urgent contraindications [44].

\section{Methods for Arrhythmia Detection}

In the methodology for the arrhythmia detection in stroke patients, a distinction must be made between inpatient treatment in a stroke unit and the time after discharge from the hospital.

\section{In the stroke unit}

As approximately 3-quarters of all relevant arrhythmias of the acute phase occur within the first $24 \mathrm{~h}$, monitoring is most effective on the first day [18]. In particular, patients with relevant neurological deficits should be monitored for at least $72 \mathrm{~h}$, especially as the severity of stroke is also an independent predictor of cardiac arrhythmias [18]. Monitoring has 2 objectives: 1 . Immediate detection of severe, hemodynamically relevant tachycardic and bradycardic arrhythmias; and 2. detection of asymptomatic arrhythmias with significance for secondary prophylaxis, in particular, detection of subclinical episodes of paroxysmal atrial fibrillation. For the first point, the systems operate with acoustic alarm signals, which can be individually activated or deactivated and whose threshold values are to be adjusted in detail. In addition to the experiences of intensive care units in internal medicine departments, for Stroke Unit it could be shown that a too liberal definition of these threshold values contributes to so-called "alarm fatigue" of the staff [45]. Monitoring of stroke patients with cognitive deficits or psychomotor restlessness often produces artifacts, that in a clinical study led to false alarms in over $90 \%$ of the arrhythmias detected by the system as suspected life-threatening episodes. It is proposed to define the threshold values for acoustic signals narrowly, thus limiting alarms to vital threats. In addition, a manual evaluation of all detected episodes is necessary regardless of acoustic alarms. For the detection of asymptomatic episodes of atrial fibrillation, continuous monitoring is significantly superior to the serial preparation of 12-lead ECG leads as well as the processing of 24-h Holter ECGs [46, 47]. In order to increase the sensitivity of monitoring, it is useful to systematically analyze the data obtained. There are 2 approaches: 1 . In the manual procedure, the ECG lead information is stored on a hard disk and evaluated on site at 24-h intervals similar to the assessment of a long-term ECG. ( $\triangleright$ Fig. 3) An important component of this approach is the preparation of frequency profiles, which allow an immediate identification of suspicious episodes by means of frequency jumps or changes in the frequency band [47]. This simple tool is included in the software of most monitoring systems at no extra cost. The evaluation in the form of a "rhythm visit" takes only a few minutes per patient and can double the sensitivity of the monitoring for the detection of paroxysmal atrial fibrillation [47]. 2 . In the case of an automated procedure, on the other hand, the raw data are derived from the monitoring system and are sent to a company which carries out the evaluation commercially and makes the results of its evaluation available to the clinic in its reports [46]. The evaluation is based on an automatic analysis of RR interval changes, but the exact functioning of the detection algorithm is a operating secret of the commercial provider. In a clinical study, however, the automatic evaluation increased the sensitivity of the monitoring, but there were 14 false-positive results and 3 false-negative findings among 496 patients [46].

\section{After discharge from the hospital}

It is estimated that around $20 \%$ of patients with cryptogenic stroke suffer from unrecognized paroxysmal atrial fibrillation. This is the starting point for an intensification of ECG monitoring beyond treatment in a stroke unit. Regular clinical examination, the patient manually checking his own pulse and processing of Holter ECG data are proposed as useful basic measures for the follow-up of these patients [48]. The pulse checked by the patient represents a simple screening instrument with few false-positive results, which can be reliably learned by the majority of stroke patients. For selected patient groups, external or implantable event recorders are available that allow continuous monitoring of cardiac rhythm over several years $[49,50]$ : In the CRYSTAL-AF study, 441 patients who had suffered an ischemic stroke within 60 days prior to study inclusion were randomized either to receive an implantable event recorder (Medtronic ${ }^{\circledR}$ Reveal XT) or standard treatment. After 6 months, with the help of the event recorder, a significantly greater number of patients with paroxysmal atrial fibrillation could be detected (HR 6.4, 95\% Cl: 1.921.7). However, it should be noted that only 88 resting ECGs and 20 Holter ECGs were performed in the control group with $n=220$ patients, which according to today's standard does not correspond to an adequate follow-up program for patients with cryptogenic stroke. The difference to the implantable event recorders should therefore be relativized if patients receive a close, non-invasive follow-up.

\section{Therapy}

\section{Basic measures}

The first-time occurrence of cardiac arrhythmias in stroke patients represents an emergency with a potentially vital threat. The important aspects of management are summarized in $>$ Table 2 . In the case of hemodynamically relevant disorders, the procedure is according to the emergency medical recommendations for on-call resuscitation team [51]. In the case of tachycardias, an emergency cardioversion may be considered, in the case of bradycardia, the beginning of a transcutaneous pacemaker stimulation or the placement of a temporary pacemaker. In the case of disturbances without immediate hemodynamic relevance, cardiorespiratory monitoring of the vital parameters, physical examination (volume status, cervical congestion, pulse deficit, auscultation), a 12-channel ECG and a laboratory-chemical diagnostics (electrolytes, blood count, renal function, myocardial marker, TSH ) should be carried out. Underling diseases that need treatment (e.g., acute myocardial infarction, aortic dissection or increase in intracranial pressure, recurring stroke) as a cause of arrhythmia must be excluded. Potentially proarrhythmogenic conditions must also be recorded and 
- Table 2 Evaluation and management of patients with acute stroke and arrhythmias.

\begin{tabular}{|c|c|c|c|}
\hline Priority & Key question & Clinical examples & Important measures (Choice) \\
\hline 1. & $\begin{array}{l}\text { Is there acute } \\
\text { cardiac } \\
\text { insufficiency? }\end{array}$ & $\begin{array}{l}\text { Low-Output: Blood pressure } \\
\text { drop, shock, syncope. } \\
\text { Backward heart failure: Lung } \\
\text { edema, peripheral edema. }\end{array}$ & $\begin{array}{l}\text { Bradycardias: Stop medications causing bradycardias, if necessary temporary pace } \\
\text { maker stimulation, initially mostly transcutaneously ( } 40-200 \mathrm{~mA} \text {, impulse breadth } \\
20-40 \mathrm{~ms}, 70 / \mathrm{Min}) \text {, atropine } 0.5-1.0 \mathrm{mg} \text { i. v. (caution: conduction block below the AV } \\
\text { node often atropine resistant). Orciprenaline } 0.25-0.5 \mathrm{mg} \text { i.v. (off-label), adrenaline } \\
0.01 \mathrm{mg} \text { i.v. } \\
\text { Tachycardias: in ventricular arrhythmias if needed emergency cardioversion (biphasic } \\
120-360 \text { J or } 360 \mathrm{~J} \text { monophasic), amiodarone } 300 \mathrm{mg} \text { i. v. over } 5 \text { min in glucose } 5 \% \text {. In } \\
\text { supraventricular or juntional tachycardias frequency control with medication } \\
\text { depending on the individual case (cf. Tabelle 3), }\end{array}$ \\
\hline 2. & $\begin{array}{l}\text { Is there an } \\
\text { underlying } \\
\text { acute illness } \\
\text { needing } \\
\text { treatment? }\end{array}$ & $\begin{array}{l}\text { Cerebral: ICP rise (usually } \\
\text { bradycardias), recurrent } \\
\text { infarction, secondary } \\
\text { cerebral hemorrhage, } \\
\text { cerebral vasospasm. } \\
\text { Cardiac: Acute myocardial } \\
\text { infarction, aortic dissection, } \\
\text { myocarditis Others: Acute } \\
\text { kidney failure, sepsis }\end{array}$ & $\begin{array}{l}\text { Laboratory parameters (especially electrolytes, renal function, blood count, CRP, TSH). } \\
\text { If necessary, exclusion of acute myocardial ischemia, coronary diagnosis, CT } \\
\text { angiography (dissection?) If necessary, cerebral imaging (CCT), specific therapy } \\
\text { depending on the findings (e. g., reduction of ICP, ventricular drainage, etc.). }\end{array}$ \\
\hline 3. & $\begin{array}{l}\text { Are there } \\
\text { predisposing } \\
\text { factors? }\end{array}$ & $\begin{array}{l}\text { Volume deficiency } \\
\text { Electrolyte disorders } \\
\text { (hypokalemia, hypomagne- } \\
\text { siemia), infections, fever, } \\
\text { hypothermia, hyperthyroid- } \\
\text { ism. }\end{array}$ & $\begin{array}{l}\text { Possibly Volume substitution, parenteral compensation of hypokalemia Magnesium } \\
\text { substitution ( } 8 \mathrm{mmol} \mathrm{Mg} 2+\text { in } 100 \mathrm{ml} \text { over } 60 \mathrm{~min} .) \text {. } \\
\text { Search for locus of infection, if necessary antibiotic therapy, targeted temperature } \\
\text { management. }\end{array}$ \\
\hline 4. & $\begin{array}{l}\text { Is there an } \\
\text { indication for } \\
\text { anticoagula- } \\
\text { tion? }\end{array}$ & $\begin{array}{l}\text { Atrial fibrillation } \\
\text { Atrial flutter }\end{array}$ & $\begin{array}{l}\text { Determination of thromboembolic risk (for non-valvular AF, for example by means of } \\
\text { CHA2DS2Vasc score) and bleeding risk (e. g., HAS-BLED score). Determination of renal } \\
\text { function. (Specific relevance: age, size of the cerebral infarction, concomitant } \\
\text { medication, cognitive deficits, renal/hepatic impairment, gastrointestinal disorders, } \\
\text { previous bleeding, etc.). }\end{array}$ \\
\hline 5. & $\begin{array}{l}\text { Is there an } \\
\text { indication for } \\
\text { specific } \\
\text { antiarrhythmic } \\
\text { therapy? }\end{array}$ & $\begin{array}{l}\text { Frequency-stabilizing vs. } \\
\text { rhythm-conserving strategy, } \\
\text { ablation techniques for } \\
\text { atrial fibrillation, AV-junc- } \\
\text { tional arrhythmias, or } \\
\text { symptomatic atrial } \\
\text { fibrillation. Supply with } \\
\text { AICD or pacemaker. }\end{array}$ & $\begin{array}{l}\text { Echocardiography, internistic co-assessment. Further diagnosis depends on the } \\
\text { individual case. In many patients with stroke and atrial fibrillation, a drug-stabilizing } \\
\text { therapy is sufficient. }\end{array}$ \\
\hline 6. & $\begin{array}{l}\text { Is there an } \\
\text { autonomous } \\
\text { dysregulation? }\end{array}$ & $\begin{array}{l}\text { Sympathetic disinhibition; } \\
\text { Autonomic neuropathy }\end{array}$ & $\begin{array}{l}\text { Measurement of heart rate variability at rest and under provocation (for example, } \\
\text { Valsalva maneuver, metronomical breathing), if appropriate indication for cardiac } \\
\text { long-term monitoring, causal clarification and treatment of autonomic neuropathy. }\end{array}$ \\
\hline
\end{tabular}

treated (volume deficiency, electrolyte disturbances, infections, fever, hypothermia, hyperthyroidism, etc.).

\section{Specific antiarrhythmic therapy}

Close cooperation between the neurologist and the cardiologist is of great importance for the selection of the optimal antiarrhythmic therapy; in particular, echocardiography is usually indispensable in this context. In deciding upon therapy, not only the severity and extent of neurological deficits of the patient, but also the exact nature of the arrhythmia, underlying cardiac diseases, renal function and any concomitant medication must be taken into account. In the clinical routine of a stroke unit, antiarrhythmic management is most frequently encountered in tachycardic atrial fibrillation. The current ESC recommendations for this indication are summarized in $>$ Table 3 [44]. Accordingly, for controlling the frequency of atri- al fibrillation in patients with no clinical signs of cardiac insufficiency and with a left ventricular ejection fraction of $>40 \%$, either ß-adrenoceptor blockers or calcium antagonists are considered as first-line drug therapy. The first target should be a resting heart rate $<110 / \mathrm{min}$. If this is not possible, the start of cardiac glycosides should also be considered.

In patients with reduced left ventricular function or signs of cardiac insufficiency calcium antagonist, have to be avoided and the dosing of the beta-blocker should be carried out with great care. Amiodarone is an effective alternative, but is used with caution due to the spectrum of its side effects [44]. In the long term, frequency-regulating therapies for thrombembolic complications and mortality are not inferior to cardiac rhythm maintaining procedures. Only when the cardiological indication is confirmed (for instance, sustained clinical symptoms despite good frequency control), 
- Table 3 Frequency control according to recommendations of ESC [44].

\begin{tabular}{|c|c|c|c|}
\hline Therapy & $\begin{array}{l}\text { Acute intravenous } \\
\text { Dosage }\end{array}$ & $\begin{array}{l}\text { Long-term oral } \\
\text { Dosage }\end{array}$ & Comments \\
\hline \multicolumn{3}{|c|}{ Beta-adrenozeptor blocker } & \multirow{3}{*}{ Side effect: Bradycardias, hypotension, AV block, bronchospasm. } \\
\hline Metoprolol & $2.5-10 \mathrm{mg}$ bolus & Up to $97.5 \mathrm{mg} 2 \mathrm{x} / \mathrm{d}$ & \\
\hline Esmolol & $\begin{array}{l}0.5 \mathrm{mg} \text { bolus, then } \\
0.05-0.25 \mathrm{mg} / \mathrm{kg} / \mathrm{min}\end{array}$ & & \\
\hline \multicolumn{3}{|c|}{ Calcium channel antagonists } & \multirow{3}{*}{$\begin{array}{l}\text { Contraindication: } \operatorname{LVF}<40 \% \text {. Relative: Combination with beta blocker. } \\
\text { Side effect: Bradycardia, hypotonia, flush, headache }\end{array}$} \\
\hline Verapamil & $2.5-10 \mathrm{mg}$ bolus & Up to $120 \mathrm{mg} 3 \mathrm{x} / \mathrm{d}$ & \\
\hline Diltiazem & $15-25 \mathrm{mg}$ bolus & Up to $120 \mathrm{mg} 3 \mathrm{x} / \mathrm{d}$ & \\
\hline \multicolumn{3}{|c|}{ Cardiac glycoside } & \multirow{3}{*}{$\begin{array}{l}\text { High serum levels proarrthythmogenic and associated with higher } \\
\text { mortality. Caution: Hypokalemia. contradiction: access. conduction } \\
\text { pathway ventricular. arrhythmias. Control of renal and liver function } \\
\text { necessary. }\end{array}$} \\
\hline Digoxin & $\begin{array}{l}0.5 \mathrm{mg} \text { bolus, up to } \\
3 \mathrm{x} / 24 \mathrm{~h}\end{array}$ & $\begin{array}{l}\text { Control levels, mostly } \\
0.1 \mathrm{mg} / \mathrm{d}\end{array}$ & \\
\hline Digitoxin & $0.4-0.6 \mathrm{mg}$ bolus & $\begin{array}{l}\text { Control levels } \\
0.05-0.3 \mathrm{mg} / \mathrm{d}\end{array}$ & \\
\hline \multicolumn{3}{|c|}{ Special indication } & \multirow{2}{*}{$\begin{array}{l}\text { In case of failure, other measures. Side effect: QT- prolongation, lung } \\
\text { fibrosis, thyroid dysfunction, cataract, skin changes. }\end{array}$} \\
\hline Amiodarone & $300 \mathrm{mg}$ in $5 \%$ glucose & $200 \mathrm{mg} / \mathrm{d}$ & \\
\hline
\end{tabular}

- Table 4 Non-vitamin-K-antagonistic oral anticoagulants in non-valvular atrial fibrillation.

\begin{tabular}{|c|c|c|c|}
\hline Substance & Standard dose & Reduced dose & Criteria for dose reduction (choose) \\
\hline Dabigatran (Pradaxa ${ }^{\circledR}$ ) & $\begin{array}{l}2 \times 150 \mathrm{mg} / \mathrm{d} \text { or } \\
2 \times 110 \mathrm{mg} / \mathrm{d}\end{array}$ & $2 \times 110 \mathrm{mg} / \mathrm{d}$ & $\begin{array}{l}\text { Concomitant medication with verapamil, age }>80 \text { years. } \\
\text { Optionally in cases of increased risk of bleeding, age }>75 \text { years, } \\
\text { creatinine clearance }<50 \mathrm{ml} / \mathrm{min} \text {, Gl disorders. }\end{array}$ \\
\hline Rivaroxaban (Xarelto ${ }^{\circledR}$ ) & $1 \times 20 \mathrm{mg} / \mathrm{d}$ & $1 \times 15 \mathrm{mg} / \mathrm{d}$ & Creatinine clearance $<50 \mathrm{ml} / \mathrm{min}$ \\
\hline Apixaban (Eliquis ${ }^{\circledR}$ ) & $2 \times 5 \mathrm{mg} / \mathrm{d}$ & $2 \times 2.5 \mathrm{mg} / \mathrm{d}$ & $\begin{array}{l}\text { Creatinine clearance }<15-29 \mathrm{ml} / \mathrm{min} \\
\text { Alternative when } 2 \text { from } 3 \text { met: Age } \\
\geq 80 \text { years } B W \leq 60 \mathrm{~kg} \text { or serum creatinine } \geq 1.5 \mathrm{mg} / \mathrm{dl} \text {. }\end{array}$ \\
\hline Edoxaban (Lixiana ${ }^{\circledR}$ ) & $1 \times 60 \mathrm{mg} / \mathrm{d}$ & $1 \times 30 \mathrm{mg} / \mathrm{d}$ & $\begin{array}{l}\text { Creatinine clearance }<50 \mathrm{ml} / \mathrm{min} \text { or } \mathrm{BW} \leq 60 \mathrm{~kg} \text { or treatment with } \\
(\mathrm{P} \text {-gp) inhibitors }\end{array}$ \\
\hline
\end{tabular}

rhythm-conserving procedures should be considered with permanent, adequate oral anticoagulation in stroke patients. For this specific indication, dronedarone is recommended [44]. In case the drug therapy fails, in the long term, invasive procedures are also used, for example, implantation of a pacemaker in combination with ablation of the $\mathrm{AV}$ node.

\section{Antithrombotic therapy}

After ischemic stroke and nonvalvular atrial fibrillation, oral anticoagulation is indicated for secondary prevention. The same recommendation applies to patients with atrial fibrillation, who can be assumed to have a comparably high risk of thrombembolism [52]. In addition to the vitamin $\mathrm{K}$ antagonists, 4 preparations are currently available from the group of non-vitamin K antagonist anticoagulants (NOAC) ( $\triangleright$ Table 4), including the direct thrombin inhibitor dabigatran as well as 3 factor Xa antagonists (rivaroxaban, apixaban, edoxaban). A meta-analysis of data on patients from clinical studies treated in the context of secondary prophylaxis of stroke has shown a superior benefit-risk ratio of NOAC as against warfarin [53]. A recent retrospective study of 118891 patients over the age of 65 indicated that intracerebral and extracranial bleeding occur more frequently among those treated with rivaroxaban compared to dabigatran [54]. However, prospective data on this subject are not available, which is why the selection of the drug has to be based on the specific features of individual patients (in particular, age, renal function, liver function, pre-existing diseases, concomitant medication, compliance, etc.) [55, 56]. A particularly critical question is the optimal time for the start of the treatment after stroke: If treatment is delayed, the patient is unprotected and exposed to a high risk of recurrence, but if the patient is anticoagulated too early, it could increase the risk of bleeding complications, or complicate acute management (e. g., hemicraniectomy in the case of a cerebral infarction). On the other hand, it is assumed that the secondary prophylactic benefit of NOAC is greatest in the peracute phase. The NOAC clinical studies do not provide any information on these issues since patients were excluded in the first few weeks after stroke due to safety concerns. For heparins in therapeutic doses, on the other hand, a high risk of bleeding is known 
from previous studies in acute stroke, which is why these rare highrisk constellations remain under strict risk-benefit assessment (e. g., mechanical valve prosthesis in mitral position, vessel dissection) [57]. Once intracranial hemorrhage is excluded by imaging studies, the start of oral anticoagulation is currently individualized, taking into account the size of the infarction, clinical condition of the patient, risk of embolism, blood pressure control, concomitant medication and other factors usually between day 1 and day 12 after cardioembolic stroke $[44,58]$.

\section{"Cryptogenic stroke" and "Embolic stroke of undetermined source" (ESUS)}

The concept of "cryptogenic stroke" is not based on a general definition. The frequently cited TOAST criteria (Trial of Org10172 in Acute Stroke Treatment [59]) included both patients without a detectable cause of stroke in addition to patients with incomplete diagnostic evaluation, as well as those with multiple competing causes [60]. In large studies, about one in 4 stroke patients were assigned to this group [60]. It is to be assumed that in many cases an unrecognized cardiac embolic source is present, for example, paroxysmal atrial fibrillation. Already clinical and demographic data can support this assumption, for example, a patient over 62 years of age or with severity of stroke $>8$ on the NIHSS without attributing the symptoms to a lacunar syndrome [61]. Biomarkers in the serum, troponin [62] and BNP [63] as well as a dilated left atrium in echocardiography [64] are also associated with cardioembolic genesis, although there is no definite evidence for this. Controversy about the adequate antithrombotic therapy after cryptogenic stroke required the definition of a new entity, the "Embolic Stroke of Undetermined Sorce, ESUS". This includes all ischemic, non-lacunar, "embolic" strokes without evidence for a stenosis of the associated vessels supplying the brain, without definitive evidence for a cardiac source of embolism and after exclusion of other causes (e. g., arteritis, dissection, migraine infarction, vasospasm, drug-associated) [65]. Whether oral anticoagulation is beneficial for these patients is currently being investigated in large placebo-controlled clinical trials against a standard therapy with thrombocyte function inhibition. If the study results are positive, a paradigm shift can be expected in antithrombotic therapy after stroke.

\section{Perspectives and Open Questions}

In many patients, cardiac long-term monitoring or the readouts of pacemaker activity have frequently detected high-frequency atrial episodes not meeting the criteria of atrial fibrillation. Although there is an increased risk of stroke in this constellation, it is controversial whether this justifies the start of anticoagulation. There are also open questions concerning the optimal management of patients who suffer a stroke under NOAC; in particular, deciding if intravenous thrombolysis is indicated is a particular challenge. Specific antidotes and coagulation tests, provided that they can be made available in an emergency situation, are becoming increasingly important in this context. Autonomic disorders in the stroke patient often remain unnoticed. If in the future it becomes possible to identify autonomic dysfunction already in the acute phase, this would be the first step towards prophylaxis of secondary complications in the long-term course after stroke.
Conflict of interest

No conflict of interest has been declared by the authors.

\section{References}

[1] Kapa S, DeSimone CV, Asirvatham SJ. Innervation of the heart: An invisible grid within a black box. Trends Cardiovasc Med 2016; 26: 245-257

[2] Coote JH, Chauhan RA. The sympathetic innervation of the heart: Important new insights. Auton Neurosci 2016; 199: 17-23

[3] Soros P, Hachinski V. Cardiovascular and neurological causes of sudden death after ischaemic stroke. Lancet Neurol. 2012; 11: 179-188

[4] Jahn K, Dichgans M. Heart-brain interaction in intensive care medicine. Dtsch med Wochenschr 2010; 135: 2347-2352

[5] Kumar S, Selim MH, Caplan LR. Medical complications after stroke. Lancet Neurol 2010; 9: 105-118

[6] Cechetto DF. Identification of a cortical site for stress-induced cardiovascular dysfunction. Integr Physiol Behav Sc 1994; 29: 362-373

[7] Schwartz PJ. Cardiac sympathetic denervation to prevent life-threatening arrhythmias. Nat Rev Cardiol 2014; 11: 346-353

[8] Noheria A, Patel SM, Mirzoyev S et al. Decreased postoperative atrial fibrillation following cardiac transplantation: the significance of autonomic denervation. Pacing Clin Electrophysiol 2013; 36: 741-747

[9] Cohn WE, Gregoric ID, Radovancevic B et al. Atrial fibrillation after cardiac transplantation: experience in 498 consecutive cases. Ann Thorac Surg 2008; 85: 56-58

[10] Wake E, Brack K. Characterization of the intrinsic cardiac nervous system. Auton Neurosc 2016; 199: 3-16

[11] Lu Z, Scherlag BJ, Lin J et al. Autonomic mechanism for initiation of rapid firing from atria and pulmonary veins: evidence by ablation of ganglionated plexi. Cardiovasc Res 2009; 84: 245-252

[12] Krogh A, Lindhard J. The regulation of respiration and circulation during the initial stages of muscular work. J Physiol 1913; 47: 112-136

[13] Critchley HD, Mathias C], Josephs $O$ et al. Human cingulate cortex and autonomic control: converging neuroimaging and clinical evidence. Brain 2003; 126: 2139-2152

[14] Duschek S, Worsching J, Reyes Del Paso GA. Autonomic cardiovascular regulation and cortical tone. Clin Physiol Funct Imaging 2015; 35: 383-392

[15] Oppenheimer SM, Gelb A, Girvin JP et al. Cardiovascular effects of human insular cortex stimulation. Neurology 1992; 42: 1727-1732

[16] Cechetto DF. Cortical control of the autonomic nervous system. Exp Physiol 2014; 99: 326-331

[17] Seifert F, Kallmünzer B, Gutjahr I et al. Neuroanatomical correlates of severe cardiac arrhythmias in acute ischemic stroke. J Neurol 2015; 262: $1182-1190$

[18] Kallmünzer B, Breuer L, Kahl N et al. Serious cardiac arrhythmias after stroke: incidence, time course, and predictors - a systematic, prospective analysis. Stroke 2012; 43: 2892-2897

[19] Rem JA, Hachinski VC, Boughner DR et al. Value of cardiac monitoring and echocardiography in TIA and stroke patients. Stroke 1985; 16: 950-956

[20] Kwok CS, Rashid M, Beynon R et al. Prolonged PR interval, first-degree heart block and adverse cardiovascular outcomes: a systematic review and meta-analysis. Heart 2016; 102: 672-680

[21] Rincon F, Dhamoon M, Moon Y et al. Stroke location and association with fatal cardiac outcomes: Northern Manhattan Study (NOMAS). Stroke 2008; 39: 2425-2431 
[22] Hilz M], Schwab S. Stroke-induced sudden-autonomic death: areas of fatality beyond the insula. Stroke 2008; 39: 2421-2422

[23] Samuels MA. The brain-heart connection. Circulation 2007; 116: $77-84$

[24] Hawkins WE, Clower BR. Myocardial damage after head trauma and simulated intracranial haemorrhage in mice: the role of the autonomic nervous system. Cardiovasc Res 1971; 5: 524-529

[25] Koppikar S, Baranchuk A, Guzman JC et al. Stroke and ventricular arrhythmias. Int J Cardiol 2013; 168: 653-659

[26] Katsanos AH, Korantzopoulos P, Tsivgoulis G et al. Electrocardiographic abnormalities and cardiac arrhythmias in structural brain lesions. Int J Cardiol 2013; 167: 328-334

[27] Stead LG, Gilmore RM, Bellolio MF et al. Prolonged QTc as a predictor of mortality in acute ischemic stroke. J Stroke Cerebrovasc Dis 2009; 18: $469-474$

[28] Bobinger T, Kallmünzer B, Kopp M et al. Prevalence and impact on outcome of electrocardiographic early repolarization patterns among stroke patients: a prospective observational study. Clin Res Cardiol 2015; 104: 666-671

[29] Friberg L, Rosenqvist M, Lindgren A et al. High prevalence of atrial fibrillation among patients with ischemic stroke. Stroke 2014; 45: 2599-2605

[30] Wolf PA, Abbott RD, Kannel WB. Atrial fibrillation as an independent risk factor for stroke: the Framingham Study. Stroke 1991; 22: 983-

[31] Watson T, Shantsila E, Lip GY. Mechanisms of thrombogenesis in atrial fibrillation: Virchow's triad revisited. Lancet 2009; 373: 155-166

[32] Brambatti M, Connolly SJ, Gold MR et al. Temporal relationship between subclinical atrial fibrillation and embolic events. Circulation 2014; 129: 2094-2099

[33] Daoud EG, Glotzer TV, Wyse DG et al. Temporal relationship of atrial tachyarrhythmias, cerebrovascular events, and systemic emboli based on stored device data: a subgroup analysis of TRENDS. Heart Rhythm 2011; 8: 1416-1423

[34] Martin DT, Bersohn MM, Waldo AL et al. Randomized trial of atrial arrhythmia monitoring to guide anticoagulation in patients with implanted defibrillator and cardiac resynchronization devices. Eur Heart J 2015; 36: 1660-1668

[35] Akoum N. New perspectives on atrial fibrillation and stroke. Heart 2016, doi:10.1136/heartjnl-2015-309066

[36] Kamel H, Okin PM, Elkind MS et al. Atrial fibrillation and mechanisms of stroke: time for a new model. Stroke 2016; 47: 895-900

[37] Chen PS, Chen LS, Fishbein MC et al. Role of the autonomic nervous system in atrial fibrillation: pathophysiology and therapy. Circul Res 2014; 114: 1500-1515

[38] Viskin S, Golovner M, Malov N et al. Circadian variation of symptomatic paroxysmal atrial fibrillation. Data from almost 10000 episodes. Eur Heart J 1999; 20: 1429-1434

[39] Sposato LA, Riccio PM, Hachinski V. Poststroke atrial fibrillation: cause or consequence? Critical review of current views. Neurology 2014; 82: $1180-1186$

[40] Scheitz JF, Erdur H, Haeusler KG et al. Insular cortex lesions, cardiac troponin, and detection of previously unknown atrial fibrillation in acute ischemic stroke: insights from the troponin elevation in acute ischemic stroke study. Stroke 2015; 46: 1196-1201

[41] Gonzalez Toledo ME, Klein FR et al. Atrial fibrillation detected after acute ischemic stroke: evidence supporting the neurogenic hypothesis. J Stroke Cerebrovasc Dis 2013; 22: e486-e491

[42] Rizos T, Horstmann S, Dittgen F et al. Preexisting heart disease underlies newly diagnosed atrial fibrillation after acute ischemic stroke. Stroke 2016; 47: 336-341
[43] Chung MK, Martin DO, Sprecher D et al. C-reactive protein elevation in patients with atrial arrhythmias: inflammatory mechanisms and persistence of atrial fibrillation. Circulation 2001; 104: 2886-2891

[44] Kirchhof P, Benussi S, Kotecha D et al. 2016 ESC Guidelines for the management of atrial fibrillation developed in collaboration with EACTS: The Task Force for the management of atrial fibrillation of the European Society of Cardiology (ESC)Developed with the special contribution of the European Heart Rhythm Association (EHRA) of the ESCEndorsed by the European Stroke Organisation (ESO). Eur Heart J 2016; 37: 2893-2962

[45] Kurka N, Bobinger T, Kallmünzer B et al. Reliability and limitations of automated arrhythmia detection in telemetric monitoring after stroke. Stroke 2015; 46: 560-563

[46] Rizos T, Guntner J, Jenetzky E et al. Continuous stroke unit electrocardiographic monitoring versus 24 -hour Holter electrocardiography for detection of paroxysmal atrial fibrillation after stroke. Stroke 2012; 43 : 2689-2694

[47] Kallmünzer B, Breuer L, Hering C et al. A structured reading algorithm improves telemetric detection of atrial fibrillation after acute ischemic stroke. Stroke 2012; 43: 994-999

[48] Kallmünzer B, Bobinger T, Kahl $N$ et al. Peripheral pulse measurement after ischemic stroke: A feasibility study. Neurology 2014; 83: 598-603

[49] Sanna T, Diener HC, Passman RS et al. Cryptogenic stroke and underlying atrial fibrillation. N Engl J Med 2014; 370: 2478-2486

[50] Gladstone D], Spring M, Dorian P et al. Atrial fibrillation in patients with cryptogenic stroke. N Engl J Med 2014; 370: 2467-2477

[51] Link MS, Berkow LC, Kudenchuk P] et al. Part 7: Adult Advanced Cardiovascular Life Support: 2015 American Heart Association Guidelines Update for Cardiopulmonary Resuscitation and Emergency Cardiovascular Care. Circulation 2015; 132 (Suppl 2): S444-S464

[52] Vadmann H, Nielsen PB, Hjortshoj SP et al. Atrial flutter and thromboembolic risk: a systematic review. Heart 2015; 101: 1446-1455

[53] Ntaios G, Papavasileiou V, Diener HC et al. Nonvitamin-K-antagonist oral anticoagulants in patients with atrial fibrillation and previous stroke or transient ischemic attack: a systematic review and meta-analysis of randomized controlled trials. Stroke 2012; 43: 3298-3304

[54] Graham D], Reichman ME, Wernecke M et al. Stroke, bleeding, and mortality risks in elderly medicare beneficiaries treated with dabigatran or rivaroxaban for nonvalvular atrial fibrillation. JAMA 2016; 176: $1662-1671$

[55] Diener HC, Aisenberg J, Ansell J et al. Choosing a particular oral anticoagulant and dose for stroke prevention in individual patients with non-valvular atrial fibrillation: part 2. Eur Heart J 2016, doi:10.1093/eurheartj/ehv643

[56] Diener HC, Aisenberg J, Ansell J et al. Choosing a particular oral anticoagulant and dose for stroke prevention in individual patients with non-valvular atrial fibrillation: part 1. Eur Heart J 2016

[57] Paciaroni M, Agnelli G, Micheli S et al. Efficacy and safety of anticoagulant treatment in acute cardioembolic stroke: a meta-analysis of randomized controlled trials. Stroke 2007; 38: 423-430

[58] Macha K, Volbers B, Bobinger T et al. Early initiation of anticoagulation with direct oral anticoagulants in patients after transient ischemic attack or ischemic. Stroke 2016; 25: 2317-2321

[59] Adams HP Jr., Bendixen BH, Kappelle LJ et al. Classification of subtype of acute ischemic stroke. Definitions for use in a multicenter clinical trial. TOAST. Trial of Org 10172 in Acute Stroke Treatment. Stroke 1993; 24: 35-41

[60] Hart RG, Diener HC, Coutts SB et al. Embolic strokes of undetermined source: the case for a new clinical construct. Lancet Neurol 2014; 13: 429-438 
[61] Suissa L, Bertora D, Lachaud S et al. Score for the targeting of atrial fibrillation (STAF): a new approach to the detection of atrial fibrillation in the secondary prevention of ischemic stroke. Stroke 2009; 40: 2866-2868

[62] Nolte CH, Scheitz JF, Endres M. Troponin elevation in ischemic stroke patients. Med Klin Intensivmed Notfallmed 2015, epub ahead of print doi:10.1007/s00063-015-0116-x

[63] Koenig MA, Puttgen HA, Prabhakaran V et al. B-type natriuretic peptide as a marker for heart failure in patients with acute stroke. Intens Care Med 2007; 33: 1587-1593

[64] Baturova MA, Sheldon SH, Carlson J et al. Electrocardiographic and Echocardiographic predictors of paroxysmal atrial fibrillation detected after ischemic stroke. BMC Cardiovas Disord 2016; 16: 209
[65] Ntaios G, Papavasileiou V, Milionis H et al. Embolic strokes of undetermined source in the Athens stroke registry: an outcome analysis. Stroke 2015; 46: 2087-2093

[66] Kishore A, Vail A, Majid A et al. Detection of atrial fibrillation after ischemic stroke or transient ischemic attack: a systematic review and meta-analysis. Stroke 2014; 45: 520-526

[67] Kapa S, DeSimone CV, Asirvatham S]. Innervation of the heart: An invisible grid within a black box. Trends Cardiovasc Med 2016; 26 : 245-257

[68] Kallmünzer B, Breuer L, Hering C et al. A structured reading algorithm improves telemetric detection of atrial fibrillation after acute ischemic stroke. Stroke 2012; 43: 994-999 